\title{
Erratum to: Traditional Chinese Medicine: Salvia miltiorrhiza Enhances Survival Rate of Autologous Adipose Tissue Transplantation in Rabbit Model
}

Li Yu ${ }^{1} \cdot$ Ruhong Zhang ${ }^{1}$ Pengfei Li ${ }^{1} \cdot$ Danning Zheng ${ }^{1} \cdot J_{i a}$ Zhou $^{1} \cdot$ Jian Wang ${ }^{1} \cdot$ Bo Zhang ${ }^{1} \cdot$ Chang Zhu'

Published online: 16 November 2015

(c) Springer Science+Business Media New York and International Society of Aesthetic Plastic Surgery 2015

\section{Erratum to: Aesth Plast Surg DOI 10.1007/s00266-015-0566-9}

The second author Ruhong Zhang was inadvertently omitted from both the pdf and $\mathrm{xml}$ versions of this article. The authors regret their error.

The online version of the original article can be found under doi:10.1007/s00266-015-0566-9.

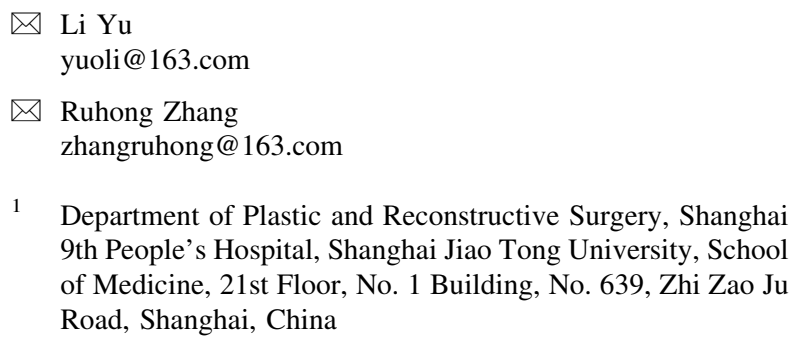

1 Department of Plastic and Reconstructive Surgery, Shanghai 9th People's Hospital, Shanghai Jiao Tong University, School of Medicine, 21st Floor, No. 1 Building, No. 639, Zhi Zao Ju Road, Shanghai, China 